\title{
Malignancies of suprapubic catheter (SPC) tracts in spinal cord injury patients: a case series and review of literature
}

\author{
Sarah Prattley ${ }^{1} \cdot$ Francesca New $^{1} \cdot$ Melissa Davies $^{1}$ \\ Received: 30 December 2018 / Revised: 1 March 2019 / Accepted: 4 March 2019 \\ (c) International Spinal Cord Society 2019
}

\begin{abstract}
Introduction Spinal cord injury (SCI) patients are at increased risk of bladder cancer. A rare variation of this is a malignancy arising or including the suprapubic catheter (SPC) tract.

Case series We present the first case series of malignancy of the SPC tract in SCI patients, including a case of mucinous adenocarcinoma, squamous cell carcinoma and sarcoma. Presentation of patients ranged from bleeding at the site of the SPC to a rapidly growing mass. All three patients were thoroughly investigated, and management was bespoke to the extent of disease and their physiological state at the time of diagnosis. This ranged from extensive surgical intervention including cystectomy, partial sigmoidectomy, excision of the abdominal wall with reconstruction and ileal conduit formation to palliation.

Discussion SCI patients represent 50\% of all known published cases of malignancy of the SPC tract. Presentation and diagnosis can be challenging; however, prompt investigation and intervention are essential given the high degree of morbidity and mortality. Routine check of the SPC site may be indicated in those patients in whom the SPC has been present for more than 5 years.
\end{abstract}

\section{Introduction}

Bladder cancer is the ninth most common cancer worldwide, with a global age-standardised incidence of 9.0 per 100,000 for men and 2.2 per 100,000 for women [1]. However, the reported incidence for bladder cancer in spinal cord injury (SCI) patients is far higher being $6 \%$ (range $0.1-10 \%$ ) [2] and is the third leading cause of death in this patient cohort [3]. A significant risk factor for the development of bladder cancer, particularly squamous cell carcinoma (SCC), is the long-term placement of a catheter either urethrally or via a suprapubic catheter (SPC) tract, particularly over 10 years $[4,5]$. A significant proportion of SCI patients use a SPC as long-term management for their urinary system and therefore this risk needs to be kept in mind.

There have been a small number of recorded cases of malignancy affecting and arising from the SPC tract itself

Sarah Prattley

sarah.prattley@nhs.net

1 Salisbury District Hospital, Odstock Road, Salisbury SP28BJ, UK
[6-17], with a significant proportion of those affected being SCI patients [17-24]. We present three patients affected with malignancy of the SPC tract being; mucinous adenocarcinoma, squamous cell carcinoma (SCC) and sarcoma. This is the first case series to date of malignancy affecting the SPC tract in SCI patients, we also present a review of the current literature.

\section{Materials and methods}

A thorough review of the literature was undertaken using; EMBASE, MEDLINE and google scholar, from inception to October 2018 for all English language articles. Search terms used were 'suprapubic catheter', 'malignancies', 'cystotomy', 'neoplasm', using the Boolean operators (and, or) to refine the search. Primary outcomes were reviewed which included age at presentation and SCI, duration of SPC catheterisation, gender, presenting symptoms, management and long-term outcome. 


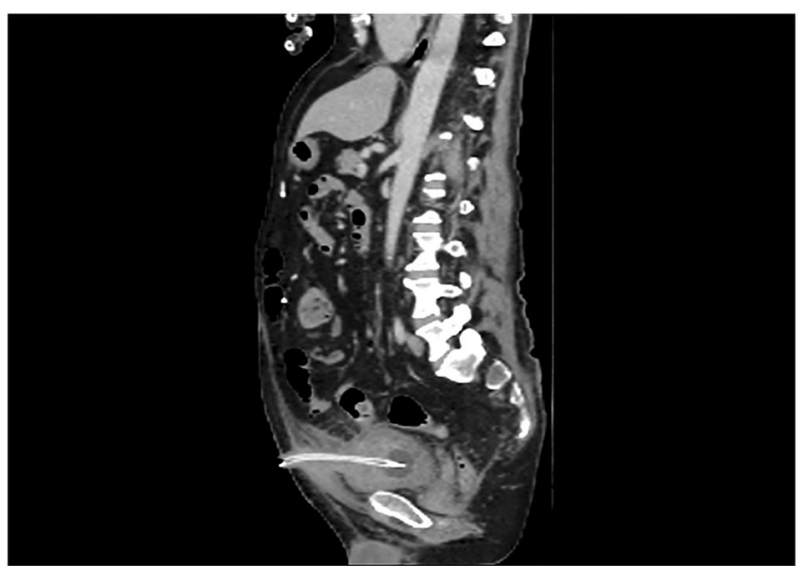

Fig. 1 Sagittal section of CT chest/abdomen/pelvis depicting invasion of malignancy into abdominal wall in Patient 1

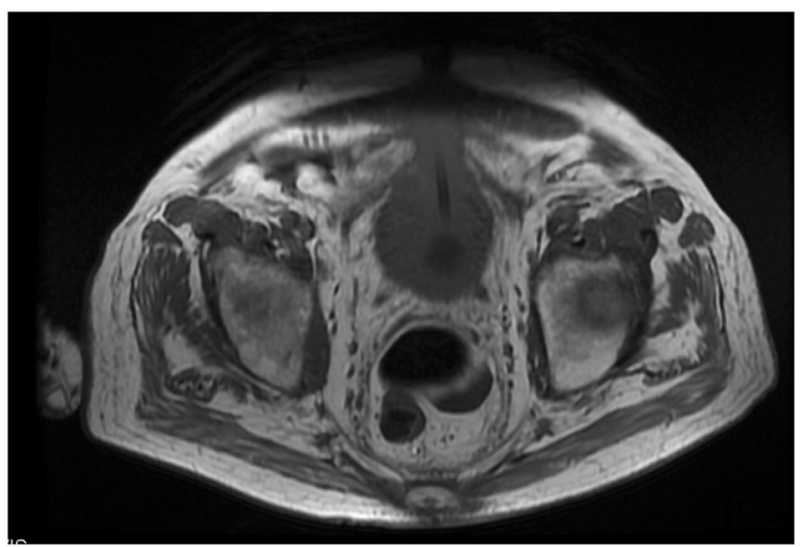

Fig. 2 MRI imaging completed for Patient 1

\section{Case series}

\section{Patient 1}

Our first patient is a 67-year-old man who presented with a short history of bleeding from his SPC site unrelated to catheter changes. He previously sustained a SCI 42 years ago; his level of neurology being C4/5 complete, ASIA grade A [25]. A SPC was inserted 8 years ago as part of the management of his neuropathic bladder. Cystourethroscopy was performed in June 2017 which demonstrated a normal bladder, histology showed only squamous metaplasia at this stage. Following this the patient presented with bleeding from the SPC tract, subsequent endoscopic evaluation in October 2017, revealed a small mass, which was biopsied. Histopathological report confirmed adenocarcinoma of bladder origin.

A CT chest/abdomen/pelvis (Fig. 1) and MRI pelvis scans (Fig. 2) were performed confirming cancer involving the SPC tract. This demonstrated new invasive disease which included invasion into the abdominal wall.

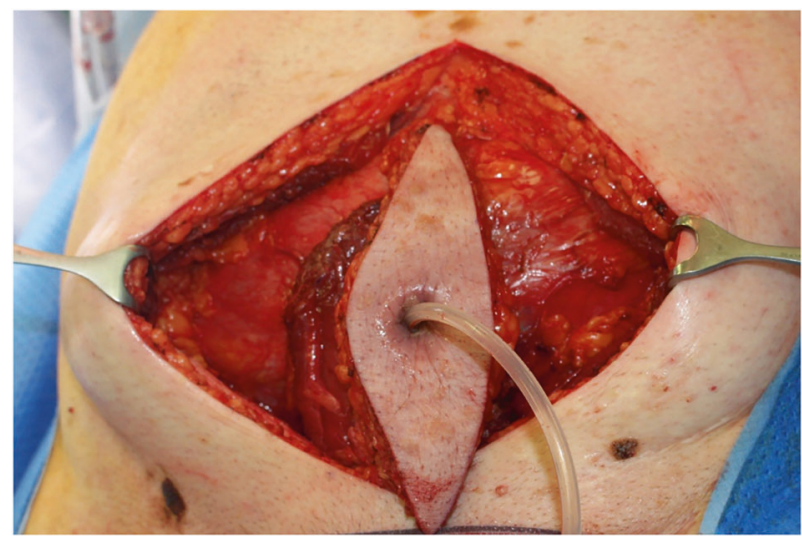

Fig. 3 En-bloc resection of SPC tract for Patient 1

An en-bloc resection including a cystoprostatectomy, anterior abdominal wall resection and removal of part of the sigmoid colon were performed (Fig. 3), as at the time of surgery cancer appeared to have spread to the sigmoid colon. He was reconstructed with a colostomy, ileal conduit and closure of the wound was with mesh and abdominoplasty.

Histology demonstrated pT3bNO adenocarcinoma, with surrounding cystitis glandularis and high-grade glandular dysplasia. Tumour was felt to have arisen from the bladder and extended into muscularis propria and SPC tract. There was an incidental finding of pT2N0 prostate adenocarcinoma Gleason $3+3$. All lymph node specimens were clear of tumour, and ureteric sections were also clear. Margins were negative.

The patient had a complex postoperative course with a planned Intensive Care unit admission due to his comorbidities and baseline requirement of overnight noninvasive ventilation. He was also pre-operatively optimised and managed for a chest infection which was incidentally found on CT scan to the left lung base [26].

\section{Patient 2}

Our second patient was a 69-year-old man at diagnosis in January 2015. He sustained a SCI secondary to a disc prolapse in 1994; his level of neurology being T4, ASIA grade C [25]. His SPC had been in situ for over a decade.

He presented with a rapidly growing lump around his SPC tract, this was investigated with an USS and a CT chest/abdomen/pelvis which demonstrated a thickened SPC tract (Fig. 4), and some enlarged inguinal lymph nodes but no metastatic disease.

An urgent cystoscopy and wedge biopsy of the SPC tract was performed within two weeks of the CT scan. This demonstrated malignant sarcoma, likely lieomyosarcoma.

He was referred urgently to the regional sarcoma unit, but due to the aggressive nature of the disease was palliated and died within 3 months of diagnosis [26]. 


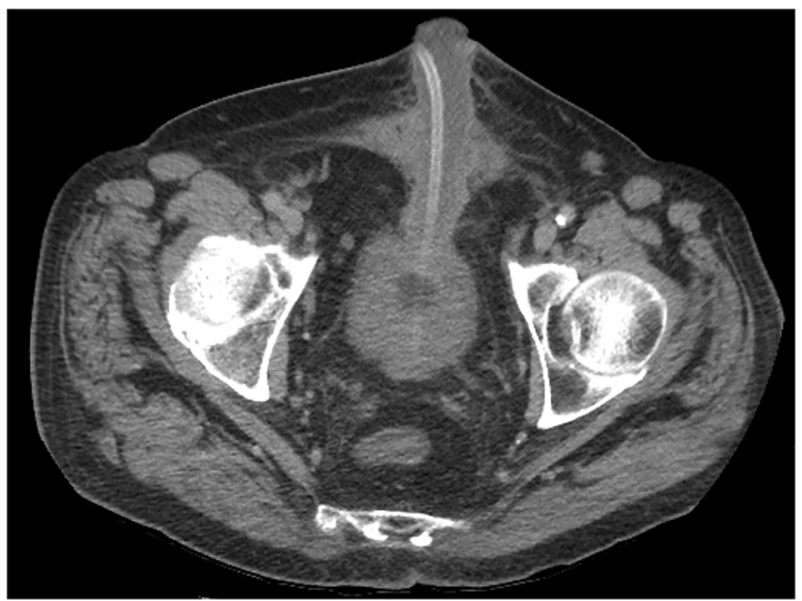

Fig. 4 CT scan for Patient 2 showing abnormal thickening of the SPC tract

\section{Patient 3}

The third patient in our series was 43 years old at diagnosis, a C7 ASIA grade A [25], tetraplegic man due to a road traffic accident in 1996. His SPC was placed thirteen years prior to diagnosis.

He attended for a routine cystoscopy and botox injection for his bladder over-activity. At the time of surgery, a mass was found and biopsied from the SPC site. This demonstrated a SCC. Two weeks later he underwent a wide local excision and removal of the SPC tract. The histology from this confirmed a SCC arising from the SPC tract with negative margins.

The patient's SPC was reinserted six months later, and he is recurrence free at 11 years [26].

\section{Discussion}

This is the first case series of malignancies involving the suparapubic tract in SCI injury patients and is the largest series in any patient group. SCI patients account for $50 \%$ of cases currently recorded of malignancy affecting the SPC tract, with 22 cases in total being reported. The majority being attributable to SCC (six cases) [17-22], followed by adenocarcinoma (three cases) [22, 23], a single case of verrucous carcinoma [24], and our case of sarcoma (Table 1).

Demographic review of SCI patients affected by malignancy of the SPC tract revealed that all patients have been male, with an average age of 58.6 years ( $\mathrm{SD} \pm 10.9$ years). The average length of time a SPC had been in place prior to presentation was 18.7 years $(\mathrm{SD} \pm 11.3$ years).

Presentation of patients with malignancy to the SPC tract can be challenging, the most common being a mass at the site or with exophytic growth around the cystostomy.
However, this presentation can lead to a protracted period before investigation is undertaken due to the assumption that this area is granulation tissue [17, 18, 23, 24]. Other signs and symptoms include bleeding or discharge from the SPC site or urethra, and lower abdominal pain or discomfort [19]. Our patients presented with a range of symptoms including bleeding from the SPC tract, a visible mass at the site of the SPC, and one noted at cystoscopy. Prompt investigation is required due to apparent aggressive nature of the disease.

Operative planning is essential [20], our first patient presented many challenges. He required pre-operative admission for optimisation due to the incidental finding of a chest infection on the CT scan. Post-operatively due to his ventilatory requirements a planned intensive care admission was arranged. A multidisciplinary approach was required for his operation involving the Urology, Colorectal and Plastic Surgery teams. Intraoperatively the cancer was felt to be invading into the sigmoid colon, therefore the affected area was resected, and a colostomy formed. The abdominal repair was carefully managed with an abdominoplasty and mesh repair.

Reported management favours surgical intervention, a combination of wide local excision, partial or full cystectomy, abdominal wall excision and reconstruction with ileal conduit formation appear to be the treatments of choice [17, $20,22,24]$. Other courses of management include radiotherapy either as radical or palliative therapy [19, 21]. Longterm outcomes for patients with malignancy of the SPC tract is poorly reported, indeed our third patient has the longest reported recurrence-free survival following surgical intervention. While the SCI population has an approximate recurrence-free survival at one year of $55 \%$, those with malignancy of the SPC tract without SCI, had an approximate mortality rate within 12 months of $67 \%$. This high level of mortality from apparent rapid disease progress, or metastatic disease at presentation is reflected by our second patient, whereby disease progression after diagnosis led to palliation and death within 3 months.

There are currently no recommended guidelines for routine follow up or flexible cystoscopy either via the urethra or SPC tract for long term catheterisation or spinal cord injury patients in the UK [27]. Therefore, a high level of suspicion is needed for patients presenting with symptoms suggestive of malignancy. At our spinal rehabilitation unit patients are typically reviewed once a year following discharge, to address their on-going management. It may be advisable to incorporate questioning into any problematic symptoms from the SPC site and an examination to ensure any suspicious features are promptly investigated, particularly in those whose SPC has been in place for increasing years. 


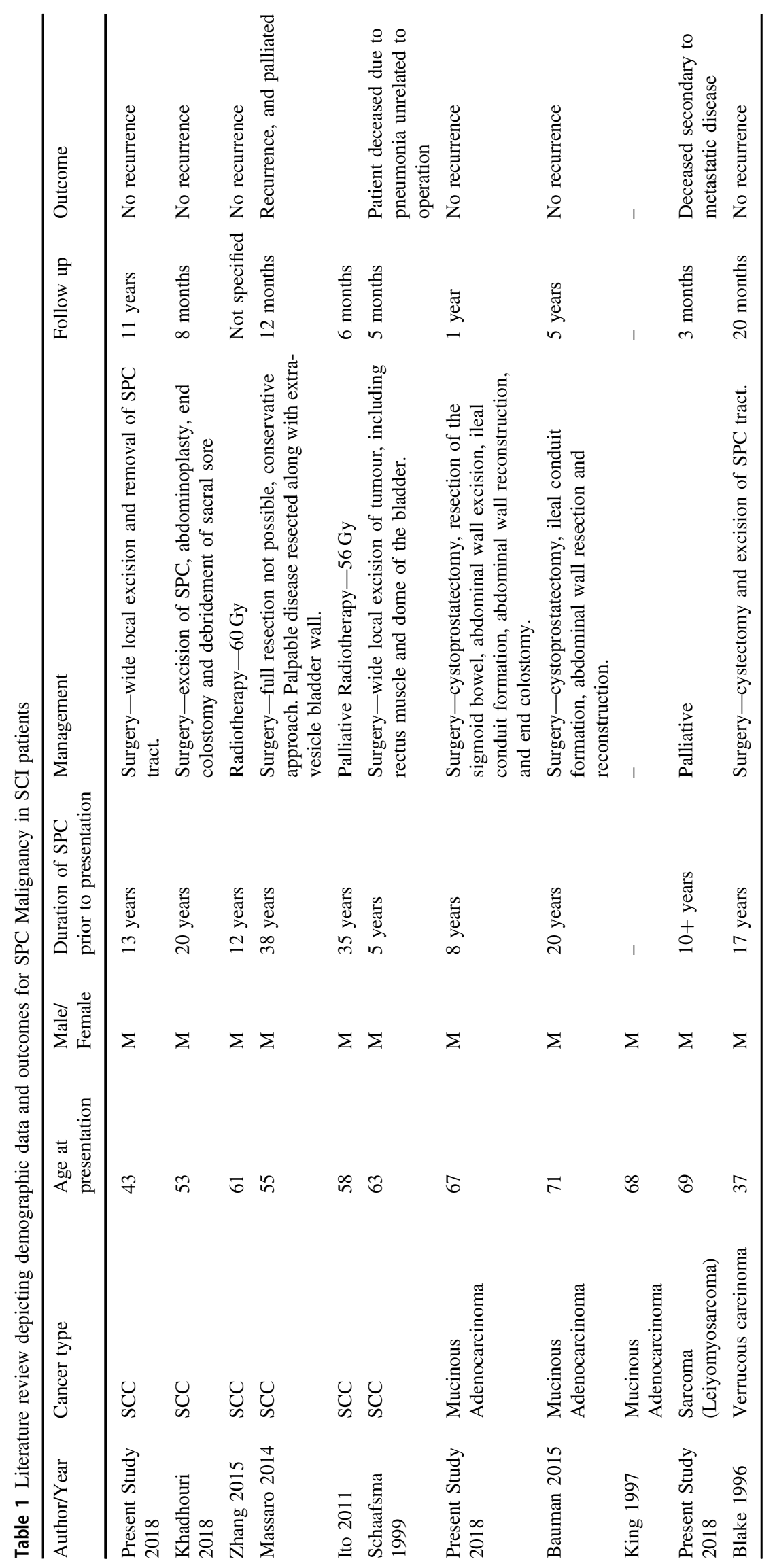




\section{Conclusion}

Malignancies of the SPC tract in SCI patients are rare, however, prompt diagnosis and early surgical intervention with careful pre- and post-operative planning is essential. Increased suspicion and level of investigation is recommended for patients who have a long-term SPC, with particular attention to any suspicious signs or symptoms.

Acknowledgements No funding was obtained for this case series.

\section{Compliance with ethical standards}

Conflict of interest The authors declare that they have no conflict of interest.

Publisher's note: Springer Nature remains neutral with regard to jurisdictional claims in published maps and institutional affiliations.

\section{References}

1. Antoni S, Ferlay J, Soerjomataram I, Znaor A, Jemal A, Fray F. Bladder cancer incidence and mortality: A global overview and recent trends. Eur Urol. 2017;71:96-108.

2. Gui-Zhong L, Li-Bo M. Bladder cancer in individuals with spinal cord injuries: a meta-analysis. Spinal Cord. 2017;55:341-5.

3. Noone AM, Howlader N, Krapcho M, Miller D, Brest A, Yu M. et al. SEER cancer statistics review, 1975-2011, National Cancer Institute. Bethesda, MD. http://seer.cancer.gov/csr/1975-2011/.

4. Cameron AP, Rodriguez GM, Schomer KG. Systematic review of urological follow up after spinal cord injury. J Urol 2012;187:391-7.

5. Navon JD, Soliman H, Khonsari F, Ahlering T. Screening cystoscopy and survival of spinal cord injured patients with squamous cell cancer of the bladder. J Urol. 1997;157:2109-11.

6. Libo M, Gui-Zhong L. Mucinous adenocarcinoma of the suprapubic cystostomy tract without bladder involvement. Urol J. 2017;14:4048-51.

7. Boaz RJ, John NT, Kekre N. Squamous cell carcinoma of the suprapubic cystostomy tract in a male with locally advanced primary urethral malignancy. Indian J Urol. 2015;31:70-72.

8. Stroumbakis N, Choudhury MS, Hernandez-Graulau JM. Squamous cell carcinoma arising from the suprapubic cystostomy site without bladder involvement. Urology. 1993;41:568-70.

9. Ranjan N, Singh RP, Ahmad A, Kumar A, Singh M. Squamous cell carcinoma arising from suprapubic cystostomy tract along with bladder involvement. Journal of Case Reports. 2015;5:327-30.

10. Gupta NP, Singh I, Nabi G, Ansari MS, Mandai S. Marjolin's ulcer of the suprapubic cytsostomy site infiltrating the urinary bladder: a rare occurrence. Urology. 2000;56:330.
11. Stokes S 3rd, Wheeler JS Jr, Reyes CV. Squamous cell carcinoma arising from a suprapubic cystostomy tract with extension into the bladder. J Urol. 1995;154:1132-3.

12. Chung JM, Hyun OhJ, Hwan Kang S, Choi S. Squamous Cell Carcinoma of the cystostomy tract with bladder involvement. Korean J Urol. 2013;54:638-40.

13. George CM, Ismail M, Khadra A. Squamous cell carcinoma of the bladder associated with short-term suprapubic catheterisation. Curr Urol. 2011;5:46-47.

14. Patel K, Hori S, Roberts J, Sengupta A. Need for early imaging in symptomatic suprapubic catheter tracts: Rare case of cutaneous squamous cell carcinoma or tract origin without bladder involvement. J. Clin Urol. 2017;10:193-6.

15. Horn T, Seidl S, Gschwend JE, Kubler H. Implantation metastasis of prostate cancer in a suprapubic cystostomy tube needle tract. Prostate Cancer Prostatic Dis. 2010;13:292-4.

16. Geok Chin T, Masir N, Noor Hussin H, Mohd Sidik S, Boon Cheok L, Yean T. Myeloid sarcoma of the urinary bladder with cutaneous tumour seeding after percutaneous suprapubic catheterization. Malays J Pathol. 2011;33:47-51.

17. Massaro PA, Moore J, Rahmeh T, Morse MJ. Squamous cell carcinoma of the suprapubic tract: A rare presentation in patients with chronic indwelling urinary catheters. Can Urol Assoc J. 2014;8:E510.

18. Schaafsma RJH, Delaere KPJ, Theunissen PHMH. Squamous cell carcinoma of suprapubic cystostomy tract without bladder involvement. Spinal Cord. 1999;37:373-4.

19. Zhang X, Mi Y, Wang D, Yuan X, Zhang B, Bai T. Highly differentiated squamous cell carcinoma arising from a suprapubic cystostomy tract in a patient with transplanted kidney. Int J Clin Exp Med. 2015;8:21770-2.

20. Khadouri S, Singh Rye D, Powari M, Daniels IR, McGrath JS. A case report of squamous cell carcinoma in a suprapubic urinary catheter tract: surgical excision and simultaneous colostomy formation. J Surg Case Rep. 2018;2:1-4.

21. Ito H, Arao M, Ishigaki H, Ohshima N, Horita A, Saito I, et al. A case of squamous cell carcinoma arising from a suprapubic cystostomy tract. BMC Urology. 2011;11:20.

22. Bauman TM, Potretzke AM, Brandes SB, Potretzke TA, Siegal CL Mucinous adenocarcinoma of the bladder associated with long term suprapubic tube: A case report. BMC Urology. 2015;15:119.

23. King DH, Barber DB, Farley NJ, Harris JM, Able AC. Mucinous adenocarcinoma arising from a suprapubic cystostomy site without bladder involvement. J Spinal Cord Med. 1997;20:244-6.

24. Blake PA, Kim CO, Lopez AE, Krongrad A. Verrucous carcinoma of a suprapubic cystostomy track. J Urol. 1996;156:174.

25. Kirshblum SC, Burns SP, Biering-Sorensen F, Donovan W, Graves DE, Jha A, et al. International standards for neurological classification of spinal cord injury (revised 2011). J Spinal Cord Med. 2011;34:535-46.

26. Prattley S, New F, Davies M. Malignancies of suprapubic catheter (SPC) tracts and a review of the literature: A case series. Poster presented at International Continence Society $48^{\text {th }}$ Annual Meeting. 2018. Philadelphia, PA.

27. Harrison SCW, Lawrence WT, Morley R, Pearce I, Taylor J. British Association of Urological Surgeons' suprapubic catheter practice guidelines. BJU Int. 2010;107:77-85. 